\title{
Multi-Hierarchical Pattern Recognition of Athlete's Relative Performance as A Criterion for Predicting Potential Athletes
}

\author{
Mohamad Razali Abdullah', Ahmad Bisyri Husin Musawi Maliki', Rabiu Muazu Musa', Norlaila Azura Kosni', \\ Hafizan Juahir ${ }^{2}$, Mainul Haque ${ }^{3}$ \\ ${ }^{1}$ Faculty of Applied Social Sciences, Universiti Sultan Zainal Abidin, 21300, Terengganu, Malaysia. \\ 2East Coast Environmental Research Institute (ESERI), Universiti Sultan Zainal Abidin, 21300, Terengganu, Malaysia. \\ ¿Unit of Pharmacology, Faculty of Medicine and Defense Health, National Defense University of Malaysia, Kem Sungai Besi, 57000 Kuala Lumpur, Malaysia.
}

\begin{abstract}
Objective: This study investigates the relative performance quality pattern of athletes that trains under Terengganu sports development program based on physical fitness and psychological components. Methods: Relative performance data $(223 \times 7)$ were obtained from various types of sport, and its main tributaries were evaluated for physical fitness and TEOSO instrument. Multivariate methods of hierarchical agglomerative cluster analysis (HACA), discriminant analysis (DA), principal component analysis (PCA), and principal factor analysis (PFA), were used to study the relative performance variations of the most significant performance quality variables and to determine the origin of relative performance components. Results: Three clusters of performance were shaped in view of HACA. Forward and backward stepwise DA discriminates six and five performance quality variables from the first seven variables. PCA and FA were used to identify the origin of each quality performance variables based on three clustered groups. Three PCs were obtained with $67 \%$ total variation for the highperformance group (HPG) region, three PCs with $72 \%$ and $64 \%$ total variances were obtained for the moderate-performance group (MPG) and low-performance group (LPG) regions, respectively. The general performance sources for the three groups are from cardiovascular and ego orien-
\end{abstract}

tation sources. The differences between groups are from flexibility for LPG, task orientation, muscle strength and endurance for MPG and for HPG is flexibility, strength and task orientation. Conclusion: Multivariate methods reveal meaningful information on the relative performance variability of a large and complex athlete's performance quality data and can be used to determine the significant source and predict potential athletes.

Key words: Cluster analysis, Discriminant analysis, Goal orientation, Principal component analysis, Physical fitness, Relative performance.

Correspondence :

Mainul Haque

Professor, Unit of Pharmacology, Faculty of Medicine and Defense Health, National Defense University of Malaysia, Kem Sungai Besi, 57000 Kuala Lumpur, Malaysia.

Phone no: + 60109265543

E-mail: runurono@gmail.com

DOI: 10.5530/jyp.2016.4.24

\section{INTRODUCTION}

In many sports, sufficient levels of physical fitness (e.g., muscle strength/ power and endurance) are necessary for the achievement of successful sport specific tasks. For instance, during competition in sports, athletes need high levels of aerobic capacity, speed, and agility, as well as maximal and explosive muscle strength to outperform their opponents. ${ }^{1}$ A particular study has gone outside the mere relationship between physical fitness and cognitive capacity, suggesting that, intellectual ability might also play a role in the successful performance of physical activity. ${ }^{2}$ This, however, signifies a novelty on expansion in research on sports science since research on perceptive expertise in the sport were mostly expected at discovering intellectual predictors of successful sports performance, recruiting new athlete and optimization of sport-specific cognitive skills through training. ${ }^{3}$ Physical fitness is considered a powerful marker of health. ${ }^{4}$ Longitudinal studies have recently contributed to the existing verification concerning physical fitness and health of youth. For example, improvements in cardiorespiratory fitness have revealed to decrease the risk of becoming overweight across puberty. ${ }^{5}$

Moreover, motivation has also reported playing a significant role in physical fitness performance of youth athlete. ${ }^{6}$ It has shown that two accomplishment goals that are task and ego associated with the capability state and that achievement are subjectively defined. ${ }^{6}$ Thus, interpretation of successful performance outcome in competition could be very diverse for multiple persons. ${ }^{7}$ Similarly, it has been suggested that both high task and high ego orientation may represent achievement oriented profile. ${ }^{8}$ It is further indicated that athletes with a high task as well as high ego orientation might gain greater chances to the attainment of success and

better adapted to meet the demands of competition. ${ }^{89}$ Although, other studies have assessed the usefulness of goal orientation in sports and athlete, as well as its association with competition and tournament.? Nonetheless, research that integrates physical fitness and goal orientation as a relative performance and uses them as a criterion predictor in the selection of potential athletes are considerably limited. Thus, this study aims to examine the relative performance quality pattern of 223 male athletes that trains under Terengganu sports development program in relation to physical fitness and psychological components.

\section{MATERIALS AND METHODS}

Participants: The participants of the current study comprised of 223 male adolescent athletes $(17.38 \pm 1.92$ years $)$. The participants were recruited from the interstate championship with various types of sports from Terengganu state in Malaysia. These athletes represented their corresponding divisions in the competition and were reflected the best at the state level for the under 21 year's age groups. These age groups were chosen because of research suggesting that participation motives and achievement behavior changes around this age. ${ }^{10}$ The measurements were carried out in the first three months of 2015. The coaches and the managers of the athletes were informed about the purpose of the research. Writing approval was obtained, and all the players signed consent forms. Procedure of Battery Tests: Anthropometric Test: Standard anthropometric testing was conducted which constitutes of height and weight with the subjects dressed in light clothing. Height was measured with a wallmounted wooden stadiometer to the nearest $0.5 \mathrm{~cm}$. Body weight was evaluated with a standardized electronic digital scale to the nearest $0.1 \mathrm{~kg}$. Body mass index (BMI) was measured as body mass in kilograms 
divided by height in meters squared $\left(\mathrm{kg} / \mathrm{m}^{2}\right)$. The measurements were obtained twice, and the mean value was generated as the final score. All the measurements were executed in accordance with ISAC protocol. ${ }^{11}$ Muscular Strength: Participants performed the sit-up test with knees bent at 90 degrees and feet flat on the floor and performed push up test with extended legs. ${ }^{12}$ The number of completed sit-ups and push-ups in 1-minute was recorded. Flexibility: The flexibility of the lower back and hamstrings was measured by the V-sit and reach test. ${ }^{13}$ The athletes performed two trials, and the best one was recorded for further analysis. Speed Test: Linear sprint speed was evaluated over $20 \mathrm{~m} \cdot{ }^{14}$ Infrared speed traps (Brower Timing system) were positioned at the start line $(0 \mathrm{~m})$ and $20 \mathrm{~m}$ at a height of around $0.5 \mathrm{~m}$ off the ground. Subjects started the test from a standing start at a distance of $0.3 \mathrm{~m}$ behind the initial timing gate before starting the test taking after a countdown from the lead researcher. The subjects were told to keep running at maximal velocity throughout the full length of time of the sprint test. To avoid a reduction in sprint speed on approach to the $20 \mathrm{~m}$ gate, a member of the coaching staff who stood on a marker $2 \mathrm{~m}$ beyond the final timing gate provided verbal encouragement throughout each effort. The subjects were told to keep up the maximal pace until passing the marker on which the mentor stood. Athletes performed two trial with the best (fastest) times utilized for statistical analysis. At least $5 \mathrm{~min}$ interval of trial were given to recover. Endurance Capacity Test: The multistage $20 \mathrm{~m}$ shuttle run was implemented to acquire the participant's predicted maximal oxygen consumption. ${ }^{15}$ Every athlete kept running for whatever length of time he could afford until could no more keep pace with the velocity of the tape. Test results for every participant were expressed as an anticipated $\mathrm{VO}_{2 \max }$ accomplished by checking the last level and ended shuttle number at the time when the participant voluntarily resigned from the test. In spite of the fact that motivation and drills of the participants might influence their scores, it is still a legitimate test in assessing maximum oxygen uptake and can be performed in considerably a large number of participants minimizing expenses and time.

\section{Study Instrument}

Motivational Test: Task and Ego Orientation in Sports instrument (TEOSQ) was adopted in this study. ${ }^{16}$ This questionnaire contains 13 items which measure an athlete's disposition to being task or ego oriented in sport. The questionnaire was translated into Bahasa Malaysia using the back-translation method, and it is validated and additionally revealed outstanding reliability in the sports fields. ${ }^{17}$ The task and ego orientation subscales demonstrated adequate internal consistency with alpha reliability coefficients of 0.82 and 0.71 , respectively. The instrument contained six-items assessing ego (e.g., "I can do better than my friends") and seven items assessing task (e.g., "I work really hard"). The feedbacks are indicated on a 5 point Likert-type scale where $1=$ strongly disagree, and $5=$ strongly agree). Data Treatment: A total of 1561 matrices sets of the data point ( 7 variables $\times 223$ datasets) were computed in this analysis. The total missing data in the matrices were very small ( 3\%) compared to the overall data recorded. For the data analysis screening, the nearest neighbor method was applied using XLSTAT 2014 add-in software. ${ }^{18}$ This method examines the distance between each point and the closest point to it. The nearest neighbor method is the simplest methods, where the end points of the gaps are used as estimates of all missing values. ${ }^{18}$ The equation applied in this method isshowninEquation 1 below. Where $y$ istheinterpolant, $x$ istheinterpolantof the time point. Meanwhile, $y_{1}$ and $x_{1}$ are the range of coordinates for starting point of the gap, and the opposite for ending points of the gap is $y_{2}$ and $x_{2}$.

$$
\begin{gathered}
y=y=y_{1} \text { if } x \leq x_{1}+\frac{x_{2}-x_{1}}{2} \\
\text { or } \\
y=y_{2} \text { if } x \leq x_{1}+\frac{x_{2}-x_{1}}{2}
\end{gathered}
$$

\section{Data Analysis}

Cluster Analysis: In this study, hierarchical agglomerative cluster analysis (HACA) was employed to identify the grouping of the relative performance pattern. HACA is a robust method to identify and categorize components or subjects (observations/population) into clusters with greater homogeneity state within the class and greater heterogeneity state among classes with regard to a predetermined selection criterion. ${ }^{19}$ Moreover, Ward's technique utilizing Euclidean distances as a degree of resemblance in HACA has shown to be a very effective technique. The finding is clarified by a dendogram, giving the clusters and their closeness. ${ }^{20}$ However, the Euclidean distance is reported as Dlink/ $\mathrm{D}_{\max }$, which represents the quotient between the linkages distances alienated by the highest distance. The quotient is commonly multiplied by 100 as a way to standardizing the linkage distance signified by the $y$-axis. ${ }^{21}$ Discriminant Analysis: The discriminant analysis (DA) controls the variables that separate among two or more clearly joined group/clusters. It builds a discriminant capacity (DF) for every group. ${ }^{22}$ DFs are figured utilizing Equation 2 below; where $i$ is the amount of groups (G), $k i$ is the constant inherent to each group, $\mathrm{n}$ is the quantity of parameters utilized to categorize $a$ set of data into a certain group, and $w j$ is the mass coefficient assigned by DF analysis (DFA) to a given parameter $(p j)$. DA was applied in this study to ascertain whether the groups vary with respect to the mean of a variable and to utilize that variable to predict group membership. Three groups for relative performance pattern (three sampling groups represents low performance, medium performance, and high performance), which were obtained and selected from HACA. The DA was put into the raw data using the standard, forward stepwise, and backward stepwise methods. These were used to construct DFs to evaluate relative performance variations in the physical fitness and motivational performance. The relative performances of the athletes were the assembled (dependent) variables whereas all the assessed components institute the independent variables. Similarly, in the forward stepwise mode, variables are counted in step by step starting with the utmost significant variable until no significant changes were obtained. In the backward stepwise mode, variables are removed step by step beginning with the less significant variable until no significant changes were obtained.

$$
f\left(G_{i}\right)=k_{i}+\sum_{j=1}^{n} w_{i j} P_{i j}
$$

Principal Component Analysis/Factorial Analysis: The most strong pattern recognition method that is generally combined with HACA is the PCA. It gives insights into the most critical parameters because of differences of relative performance components that explain the entire data set by lessening huge parameters with a considerable slightest loss of the original data. ${ }^{23}$ The principle component (PC) can be stated as Equation 3 below;

$$
z_{i j}=a_{i l} x_{1 j}+a_{i 2} x_{2 j}+\cdots+a_{i m} x_{m j}
$$

where $z$ is the element score, $a$ is the element stacking, $x$ is the assessed estimation of the variable, $i$ is the element number, $j$ is the subject number, and $m$ is the aggregate number of variables. The FA is generally 


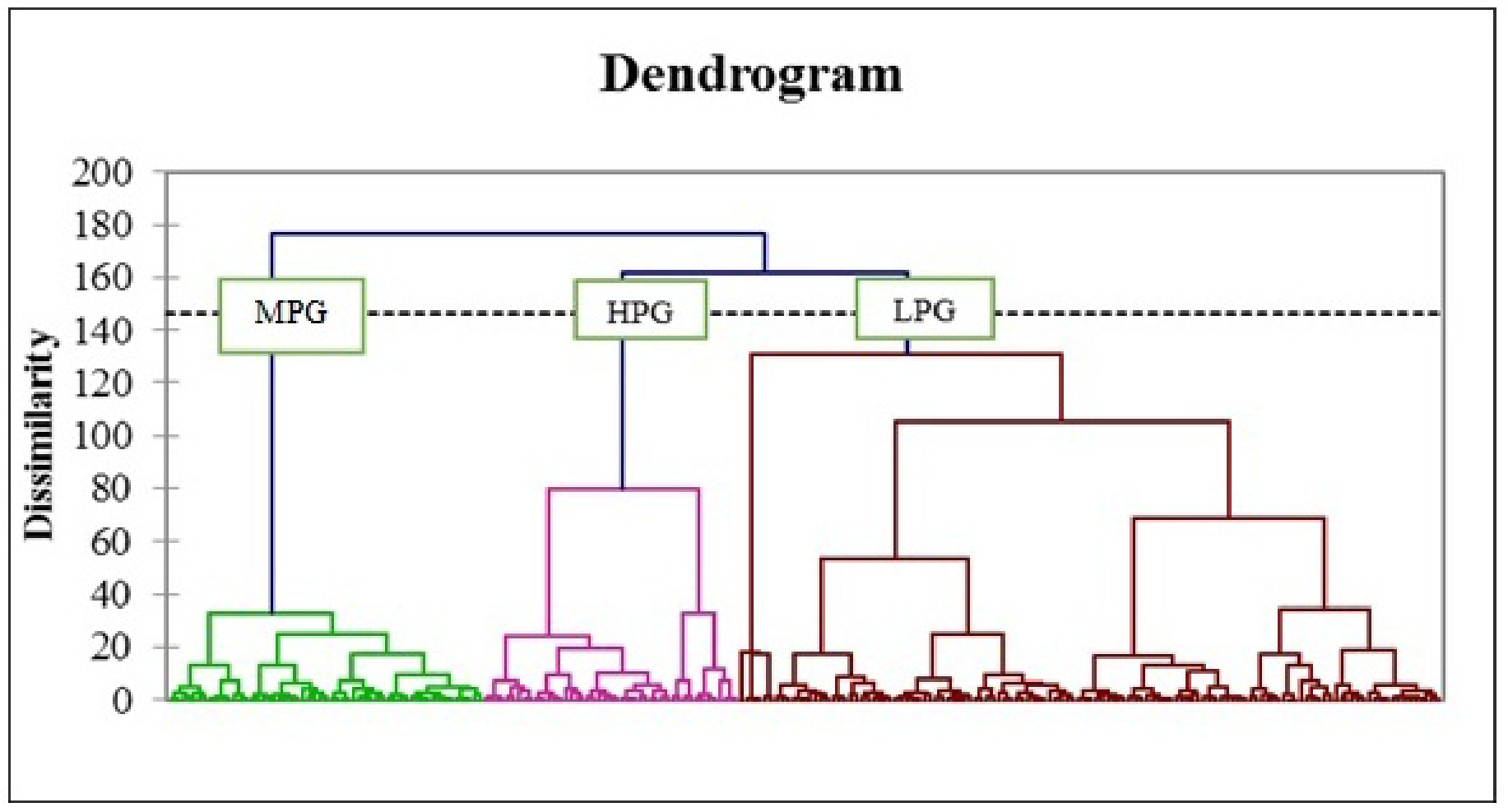

Figure 1: Dendogram of different clusters of relative performance of the athletes.

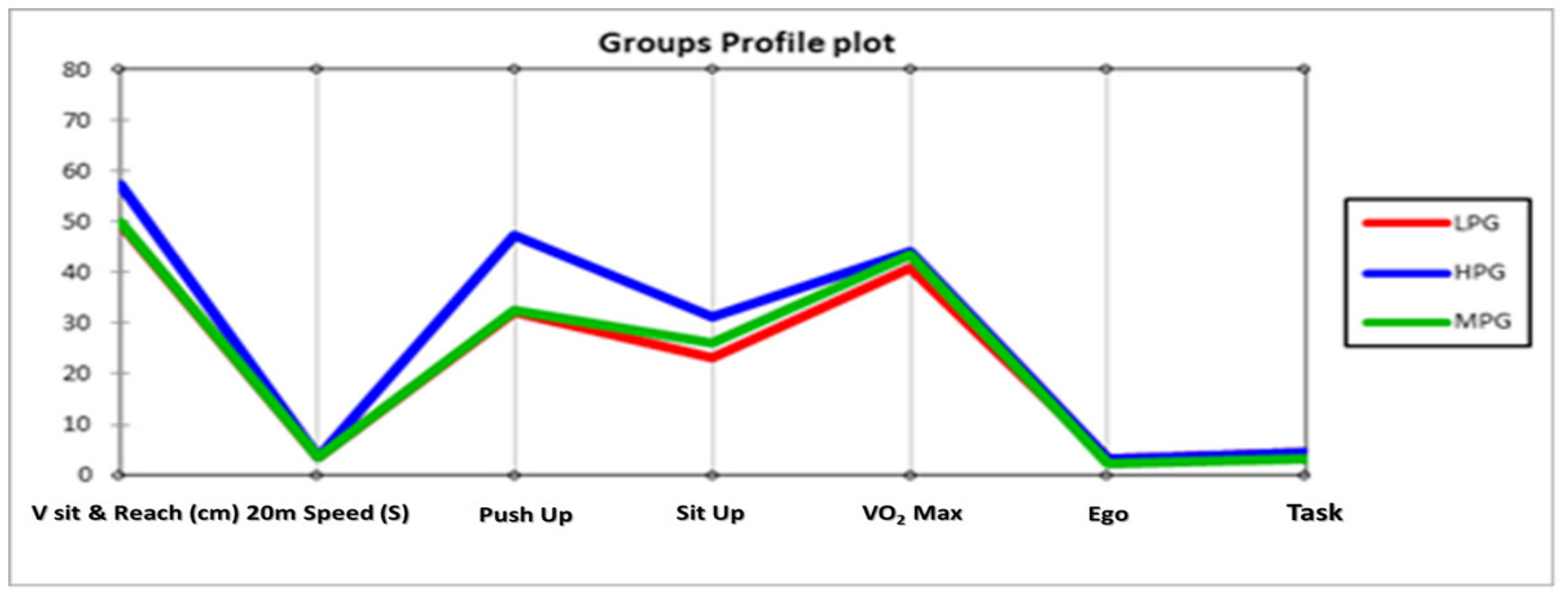

Figure 2: Groups profile plot of different clusters of the relative performance of the athletes. 


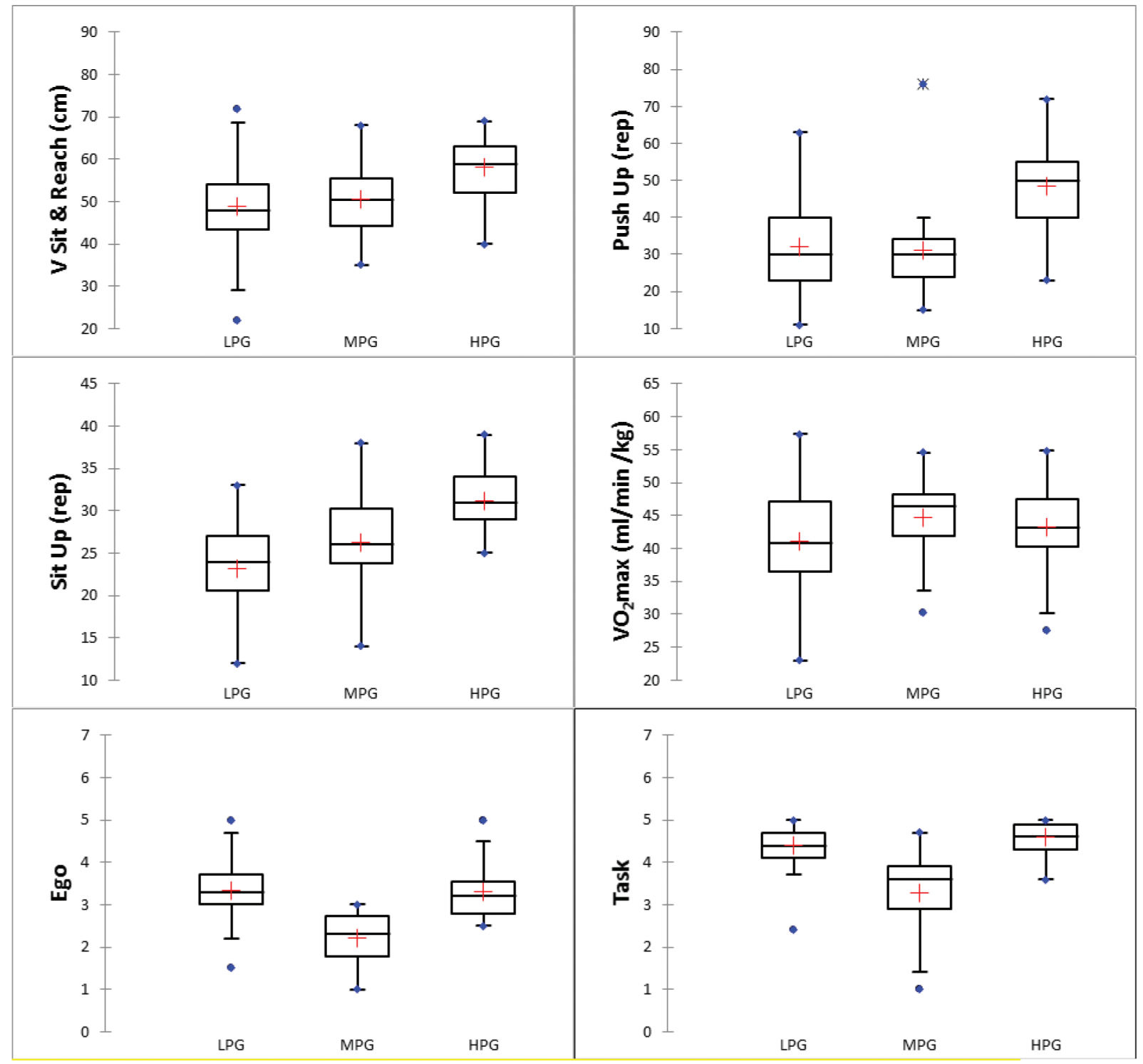

Figure 3: Box and whisker plots based on backward stepwise methods in DA.

connected as a strategy to translate a substantial complex information framework and offers a capable method for recognizing likenesses among variables or subjects. ${ }^{24}$ The PCs created by PCA are not usually promptly deciphered; for this reason, it is prudent to turn the PCs by varimax rotation. Varimax rotation identifies by the PCs with eigenvalues more than $1(>1)$ are viewed as significant for the purpose of obtaining new variables called varimax factors (VFs). ${ }^{25}$ The quantity of VFs acquired by varimax rotation is equivalent to a number of variables as per basic components and can incorporate unobservable, hypothetical, and latent variables. However, the source recognizable proof of various games was made on the premise of various athletes in the state under study. The fundamental idea of FA is communicated as;

$$
z_{i j}=a_{f 1} f_{1 i}+a f_{2} f_{2 i}+\cdots+a_{f m} f_{m i}+e_{f i}
$$

where $z$ is the measured value of the variable, $a$ is the factor loading, $f$ is the factor score, $e$ is the residual term detecting for errors or other sources of variation, $i$ is the subjects number, $j$ is the variable number, and $m$ is the total number of factors. In the current study, PCA/FA was applied to the normalized data sets (7 variables) separately for the three different groups, HPG (High-Performance Group), MPG (MediumPerformance Group), and LPG (Low-Performance Group), as delineated by the HACA technique. The output from DA in backward stepwise method (variables $\times$ cases) was used as an input for PCA/FA for each group, $6 \times 56$ for HPS, $6 \times 40$ for MPS, and $6 \times 127$ for LPS groups to identify the most significant pattern in each group.

\section{RESULTS}

Table 1 exhibits the descriptive statistics of the athletes. It shows the total number of the athletes 223 drawn from different sports. The minimum and maximum scores of all the athletes, as well as mean and standard deviations, are projected. Figure 1 shows the classification of the athletes in relation to their performance group determined by HACA, which is based on the resemblance level of the relative performance. Figure 2 displayed a group's profile plot of each cluster of relative performances. The figure describes the performances of the athletes based on the variables examined. From the Figure 2, it can be seen that the HPG (blue color), has the highest performance across all the variables tested. Similarly, the MPG (green color) has the moderate performance based on the vari- 
Table 1: Descriptive statistic of Terengganu youth male athletes

\begin{tabular}{lccccc}
\hline Variables & N & Min & Max & M & SD \\
\hline Age (year) & 223 & 13.00 & 21.00 & 17.38 & 1.92 \\
Weight $(\mathrm{kg})$ & 223 & 23.00 & 122.00 & 60.29 & 13.32 \\
Height $(\mathrm{cm})$ & 223 & 126.70 & 187.00 & 166.90 & 8.39 \\
BMI & 223 & 14.33 & 36.47 & 21.51 & 3.89 \\
V sit \& reach (cm) & 223 & 22.00 & 72.00 & 51.51 & 8.86 \\
20M speed (s) & 223 & 2.08 & 3.99 & 3.45 & 0.30 \\
Push up (reps) & 223 & 11.00 & 76.00 & 36.07 & 13.53 \\
Sit up (reps) & 223 & 12.00 & 39.00 & 25.74 & 5.71 \\
Predicted VO ${ }_{2 \max }(\mathrm{ml} / \mathrm{min} / \mathrm{kg})$ & 223 & 23.00 & 57.40 & 42.28 & 6.92 \\
Ego & 223 & 1.00 & 5.00 & 3.12 & 0.74 \\
Task & 223 & 1.00 & 5.00 & 4.24 & 0.69 \\
\hline
\end{tabular}

\begin{tabular}{|c|c|c|c|c|}
\hline \multirow{2}{*}{ Sampling groups } & \multirow{2}{*}{$\%$ Correct } & \multicolumn{3}{|c|}{ Groups assigned by DA } \\
\hline & & LPG & MPG & HPG \\
\hline \multicolumn{5}{|c|}{ Standard mode (six independent variables) } \\
\hline LPG & $91.06 \%$ & 112 & 3 & 8 \\
\hline MPG & $80.00 \%$ & 9 & 0 & 46 \\
\hline HPG & $83.64 \%$ & 9 & 36 & 0 \\
\hline Total & $87.00 \%$ & 130 & 39 & 54 \\
\hline \multicolumn{5}{|c|}{ Backward stepwise (six independent variables) } \\
\hline LPG & $88.62 \%$ & 109 & 4 & 10 \\
\hline MPG & $80.00 \%$ & 9 & 0 & 46 \\
\hline HPG & $83.64 \%$ & 9 & 36 & 0 \\
\hline Total & $85.65 \%$ & 127 & 40 & 56 \\
\hline \multicolumn{5}{|c|}{ Forward stepwise (five independent variables) } \\
\hline LPG & $88.62 \%$ & 109 & 5 & 9 \\
\hline MPG & $82.22 \%$ & 9 & 0 & 46 \\
\hline HPG & $83.64 \%$ & 8 & 37 & 0 \\
\hline Total & $86.10 \%$ & 126 & 42 & 55 \\
\hline
\end{tabular}

ables examined while the LPG (red color) has the lowest performance across all the variables tested. These grouping enabled the classification and assignation of the performance related components to the athletes and consequently lead us to the further analysis for confirmation and differentiating the athletes.

Table 2 shows the discriminant analysis conducted for the further analysis. The DA was applied on clusters defined by HACA in order to look through variation of relative performance. The clusters act as the dependent variable, whereas relative performance parameters were treated as independent variables. Standard, backward stepwise and forward stepwise mode methods were selected to perform the DA. The precision of classification using standard, backward stepwise and forward stepwise were $87.0 \%$ (six independent variables), $85.7 \%$ (six independent variables) and $86.1 \%$ (five independent variables), respectively. Box and whisker plots of these six relative performance parameters are shown in
Figure 2 from the DA via backward stepwise. Also, we found that 56 athletes are isolated to HPG, 40 athletes in MPG and 127 athletes in LPG. As explained above, Figure 2 projects the differences in six parameters between the three identified groups.

Table 3 shows the PCA conducted after the varimax rotation. The table projects the various performance related variables in association to the performances of the athletes in the three groups categorized earlier by the cluster analysis. It can be observed from the table that, the three performance groups namely; (LPG), (MPG) as well as (HGP) are attributed to some specific performance related components. From each of the identified factors based on the group, performance contains varifactors (VFs) that are defined by the components. These varifactors represents each of the components in relation to the performances of the group. Nevertheless, we standardized VFs with absolute values greater than 0.75 as the selection threshold due to the fact that these values are consider- 
Table 3: The factor loadings after PCA varimax-rotation on three performance group

\begin{tabular}{|c|c|c|c|c|c|c|c|c|c|}
\hline \multirow{2}{*}{ Variables } & \multicolumn{3}{|c|}{ LPG } & \multicolumn{3}{|c|}{ MPG } & \multicolumn{3}{|c|}{ HPG } \\
\hline & VF1 & VF2 & VF3 & VF1 & VF2 & VF3 & VF1 & VF2 & VF3 \\
\hline V Sit \& Reach $(\mathrm{cm})$ & 0.087 & 0.053 & 0.907 & 0.232 & -0.373 & -0.491 & 0.330 & -0.098 & -0.813 \\
\hline 1 Minute Push Up (reps) & -0.714 & 0.415 & 0.068 & 0.904 & -0.010 & 0.243 & 0.289 & -0.178 & 0.780 \\
\hline 1 Minute Sit Up (reps) & 0.008 & 0.627 & 0.027 & 0.115 & -0.226 & 0.848 & -0.141 & -0.655 & 0.155 \\
\hline Predicted $\mathrm{VO}_{2 \max }(\mathrm{ml} / \mathrm{min} / \mathrm{kg})$ & -0.021 & 0.823 & -0.049 & 0.126 & 0.832 & -0.100 & 0.783 & -0.151 & 0.049 \\
\hline Ego & 0.785 & 0.098 & 0.172 & -0.398 & 0.763 & 0.021 & -0.196 & 0.809 & 0.119 \\
\hline Task & 0.564 & 0.212 & -0.477 & -0.822 & 0.150 & 0.312 & 0.680 & 0.482 & -0.135 \\
\hline Eigen value & 1.522 & 1.271 & 1.047 & 2.073 & 1.208 & 1.067 & 1.573 & 1.296 & 1.165 \\
\hline Variability (\%) & 25.370 & 21.177 & 17.447 & 34.553 & 20.127 & 17.791 & 26.225 & 21.593 & 19.424 \\
\hline Cumulative \% & 25.370 & 46.547 & 63.994 & 34.553 & 54.68 & 72.471 & 26.225 & 47.818 & 67.242 \\
\hline
\end{tabular}

ably solid and stable, which indicates moderate to strong loadings on the extracted factors in the current study. However, it can be seen from the Table 3 that a total of nine components were identified as the most significant from the performances of the three groups. These components, however, differentiate the groups based on their level of performance to the related components examined in this study.

\section{DISCUSSION}

The result obtained from the current study implies that flexibility, muscular strength, core body strength, cardio vascular endurance and mastery in performance were found to be the most significant variable, and therefore, all these six parameters tend to possess high variation regarding the performance attributed to the groups. This finding is in agreement with the previous study which inferred that for any successful performance in sports, certain fundamental variables are required. ${ }^{26}$ It has been indicated that endurance to respond to the demand of the game; the muscular strength, the ability for the muscle to stretch and contract from its axis and core body strength help athletes in various types of sports to perform well and hence reduce the risk of injuries. Likewise, research has shown that mastery in any sports is a secret behind the success of the athletes. ${ }^{27}$ Mastery induces confidence and consequently lead the athletes to become an expert in any type of sport they engage in.

Moreover, the finding of the current study from the PCA of LPG group indicates that ego is an essential component required for athletes of different sports. This finding is in concord with the previous study which reported that athletes can succeed in their sports when they have an adequate level of ego to perform. ${ }^{28}$ When athletes feel confident, they are more freely able to turn sporting potential into greater performance. Equally, when they feel unsure of themselves, the slightest setback or smallest obstacle can have an undue effect on their performance. Similarly, the finding corresponds with that of Davies and colleague who revealed that ego is the certainty of feeling that you are equal to the task at hand..$^{28}$ This sureness is measured by absolute belief in ability. However, the finding from the same group reveals that the group differs from others in relation to their relative performance of cardiovascular endurance. Cardiovascular endurance is an important fundamental attribute of athletic performance since the heart controls the oxygen flow to all the working muscles. ${ }^{29}$ Therefore, cardiovascular endurance has a direct impact on athlete's performance in various types of sports. This finding is related to the previous investigation which reported that cardiovascular fitness enhances the ability of the heart and lungs to supply oxygen-rich blood to the working muscles which in turn accelerates the actions of the athletes to act in response to the fitness requirement of the sport he or she participates in. ${ }^{30}$ Conversely, the finding from this group discloses that the group varies from the other groups based on their performance on flexibility test. Flexibility is adynamic that enable and individual to execute everyday endeavors with relative ease. Better flexibility may improve performance in aerobic training and muscular conditioning as well as in sports. ${ }^{31}$ However, there is scientific evidence that demonstrates the prevalence of injury decreases on athletes who possess greater flexibility as opposed to the athletes with lesser flexibility. ${ }^{32}$ Improved flexibility can enhance the ability of the athletes to move unconstrained through a wider range of motion. Nevertheless, the current finding is also supported by another study which stated that flexibility is one of the main fitness parameters imperative for success in many sports. $^{33}$

The finding of the current study from MPG group reveals that the group is characterized by higher muscular strength in comparison to the other groups. Upper muscular strength is considered as a force that is generated in the process of contraction of muscles or muscles group. This finding is in agreement with the previous study which reported that athletes require upper muscle strength to sustain sporting activities especially in sports requiring the utilization of upper extremities for over a longer time. ${ }^{34}$ Furthermore, the finding from the same group reveals that the group is attributed to the higher level of endurance. Endurance in athletic perspective is the ability of the athletes to sustain sporting activities for a longer duration without showing any undue fatigue. In the same direction with this finding, the previous study discloses that in a competitive athletic season, the athletes who possess a higher level of endurance are reported to have an edge over their opponents with a lesser standard of endurance. ${ }^{35}$ However, the finding from this group also indicated that the group is recognized by higher core muscles strength as opposed to the other groups. Core muscle strength is the ability of the abdominal muscles to sustain frequent activation without getting fatigue quickly. This finding is supported by the other researchers who inferred that core muscles strength is a desirable element across all sporting activities because it helps an athlete to move freely and maintain good posture during sports performance. ${ }^{36}$

The finding from HPG reveals that the group is attributable to high capacity in cardiovascular endurance. This result is similar to the previous study which indicated that cardiovascular endurance provides athletes with energy to carry out their sporting activities with vigor. ${ }^{35}$ Moreover, cardiovascular endurance is a must have component for involvement in any type of sports. Similarly, the finding from this group also indicates that HPG is recognized with a high level of self-confidence. Self-confidence is the ability of the athletes to confront their opponents without 
any feeling of fear or intimidation. This finding is congruent with some study which reported that self-confidence differentiates between the highly successful and less successful athletes. ${ }^{27-28}$ At a higher athletic level of performance, self-confidence contributes to the success of athletes which also determine whether athletes can give up or remain focused on their objectives after a series of setbacks. Additionally, flexibility is shown as the features of the athletes belonging to the HPG. Flexibility refers to the capability of the muscles at a joint to extend to their fullest capacity and consequently return to the normal status with a considerable ease. This finding is consistent with another study which indicated that a wider range of motion is needed for a successful athletic performance, this is because it helps athletes to perform actions freely and hence reduces the risk of injury occurrences among athletes. ${ }^{37}$ It describes that the more the muscular exhaustion, the less the range of motion at that particular muscular joints.

\section{CONCLUSION}

The reason of this study was to investigate the relative performance quality pattern of 223 male athletes that trains under Terengganu sports development program in relation to physical fitness and psychological components. We gathered relative performance data $(223 \times 7)$ from various types of sport, and its main tributaries were evaluated with physical fitness parameters (push up, sit up, V-sit and reach, speed and shuttle run) and the athlete's responses from TEOSQ instrument (ego and task orientation). We applied multivariate methods, namely, the HACA, the DA, the PCA, and the FA, to study the relative performance variations of the most significant performance elements and to find out the source of relative performance components. Seven relative performance quality parameters were initially selected and analyzed. The HACA identified three groups based on their performance on the parameters examined in this study. These groups are LPG, MPG, and HPG respectively. DA iden- tified six parameters ( $\mathrm{v}$-sit and reach, push up, sit up, Predicted $\mathrm{VO}_{2 \max }$, Ego, and Task) that differentiate all the groups. The finding of this study, however, identified a total number of 56 potential athletes out of 223 through the backward stepwise method of PCA. Furthermore, the PCA and FA (varimax function) revealed the origin as well as the patterns of each quality performance variables based on three clustered groups. The results of this study imply that the application of multivariate analysis is vital in identifyingan essential performance parameters in the variety of games which can save time, energy and cost.

\section{PRACTICAL IMPLICATIONS}

The findings of the present study can be valuable for coaches and sports managers to determine the most significant performance related indicators necessary for successful performance of athletes in various sports and to assist in predicting potential future athletes. Moreover, The MultiHierarchical Pattern Recognition method can also be useful in filtering as well as a selection of players (talent identification).

\section{ACKNOWLEDGEMENTS}

The authors thank the Research and Development Management Unit, University of Sultan Zainal Abidin (UniSZA), Kuala Terengganu for providing the research grant for the study (UniSZA/1/2015/SRGS/3/ RR179). The authors also express their gratitude to the Terengganu State Sports Council for their support in this research. Moreover, the authors are grateful to all team managers, coaches as well as the athletes for their help and cooperation throughout the data collection process.

\section{CONFLICT OF INTEREST}

Authors declared that there was no any conflict of interest.

\section{ABBREVIATIONS USED}

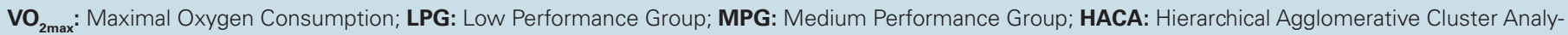
sis; DA: Discriminant Analysis; PCA: Principal Component Analysis; PFA: Principal Factor Analysis.

\section{ABOUT AUTHORS}

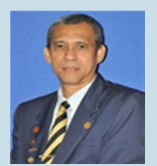

Mohamad Razali Abdullah: Obtained his Bachelor of Physical Education in 1989 from the University Putra of Malaysia, Master of Science in Sport and Exercise Science from University of Wales Institute, Cardiff in 1998 and Doctor Philosophy of Sports Science in 2007 from the University Putra of Malaysia. His interests were motor control, sports biomechanics and motor performance. He is currently working as lecturer at Faculty of Applied Social Sciences, University of Sultan Zainal Abidin, Kuala Terengganu, Malaysia.

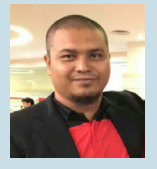

Ahmad Bisyri Husin Musawi Maliki: Is a Master student at University Sultan Zainal Abidin (UniSZA) Malaysia. He obtained his bachelor degree at University of Malaya in 2008 in Sport Science. His current research focused on scientific method in prediction of potential athletes. His research interests comprise of talent identification, test and measurement, motor learning as well as sports psychology.

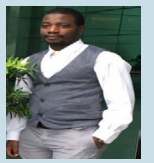

Rabiu Muazu Musa: Is a doctoral student at University Sultan Zainal Abidin (UniSZA). He obtained his bachelor degree at Bayero University Kano, Nigeria in Physical and Health Education in 2011 and graduated in Master of Sport Science at UniSZA in 2015. His doctoral research focused on developing a model for athletic performance. His research interests include performance analysis, sports psychology, exercise science, health education, talent identification and test and measurement. 


\section{REFERENCES}

1. Ziv G, Lidor R. Vertical jump in female and male basketball players-A review of observational and experimental studies. J Sci Med Sport. 2010;13(3): 332-9

2. Moreau D, Conway AR. Cognitive enhancement: a comparative review of computerized and athletic training programs. Int Rev Sport Exerc Psycho. 2013;6(1):155-83.

3. Moran A. Cognitive psychology in sport: Progress and prospects. Psychol Sport Exerc. 2009;10(4):420-6.

4. Kotlo A, Maram A, Muragundi PM, Janodia M, Ligade V. Health Related Quality of Life among Medical Representatives. J Young Pharm. 2016;8(1):18-22.

5. Ortega FB, Ruiz JR, Castillo MJ. Physical activity, physical fitness, and over weight in children and adolescents: evidence from epidemiologic studies. Endocrinol Nutr. 2013; 60(8):458-69.

6. Nicholls JG. 1989. The competitive ethos and democratic education. London UK. Harvard University Press.

7. Hodge K, Petlichkoff L. Sport Psychology Goal profiles in sport motivation: A cluster analysis. J Sport Exercise Psychol. 2000;22(3):256-72.

8. Duda JL. Toward a developmental theory of children's motivation in sport J Sport Psychol. 1987;9(2):130-45

9. Duda JL, Treasure DC. Toward optimal motivation in sport: Fostering athletes competence and sense of control. Appl Sport Psychol. 2001;4(1):43-62.

10. Phillips AC, Weiss MR. Adolescents' Achievement Beliefs and Behaviors in Sport, Music, and Reading Domains. J Sport Behav. 2016;39(1):51-71.

11. Marfell-Jones MJ, Stewart AD, de Ridder JH. 2012. International standards for anthropometric assessment. Underdale, Australia. International Society for the Advancement of Kinanthropometry.

12. Reilly T. Assessment of sports performance with particular reference to field games. Euro J Sport Sci. 2001;1(3):1-12.

13. Cuberek R, Machová I, Lipenská M. Reliability of $\vee$ sit-and-reach test used for flexibility self-assessment in females. Acta Gymnica. 2013;43(1):35-9.

14. Russell M, Tooley E. Anthropometric and performance characteristics of young male soccer players competing in the UK. Serbian J Sports Sci. 2011;5(4):155 62.

15. Leger LA, Mercier D, Gadoury C, Lambert J. The multistage 20 metre shuttle run test for aerobic fitness. J Sports Sci. 1988;6(2):93-101.

16. Duda JL, Nicholls JG. Dimensions of achievement motivation in schoolwork and sport. J Educ Psychol. 1992;84(3):290-9.

17. Xiang $P$, Lee A. Achievement goals, perceived motivational climate, and students' self-reported mastery behaviors. Res Quarterly Exercise Sport 2002;73(1):58-65

18. Azid A, Juahir H, Latif MT, Zain SM, Osman MR. Feed-forward artificial neura network model for air pollutant index prediction in the southern region of Peninsular Malaysia. J Environ Prot 2013. 2013;6(4):1-10.

19. McKenna JE. An enhanced cluster analysis program with bootstrap significance testing for ecological community analysis. Environ Model Softw. 2003;18(3):205-20

20. Forina $M$, Armanino $C$, Raggio V. Clustering with dendrograms on interpretation variables. Anal Chim Acta. 2002; 454(1): 13-19.

21. Shrestha S, Kazama F. Assessment of surface water quality using multivariate statistical techniques: A case study of the Fuji river basin, Japan. Environ Modelling Software. 2007;22(4):464-75

22. Johnson RA, Wichern DW. 1992. Applied multivariate statistical analysis. $3^{\text {rd }}$ Edition, New Jersey, USA. Prentice hall.

23. Kannel PR, Lee S, Kanel SR, Khan SP. Chemometric application in classification and assessment of monitoring locations of an urban river system. Anal Chim Acta. 2007;582(2):390-9.

24. Reghunath R, Murthy TS, Raghavan BR. The utility of multivariate statistical techniques in hydrogeochemical studies: an example from Karnataka, India. Water Res. 2002;36(10):2437-42.

25. Kim JO, Mueller CW. 1978. Introduction to factor analysis: What it is and how to do it (No 13). California, USA. Sage Publication Inc.

26. Limonta E, Cè E, Gobbo M, Veicsteinas A, Orizio C, Esposito F. Motor unit activation strategy during a sustained isometric contraction of finger flexor muscles in elite climbers. J Sports Sci. 2016;34(2):133-42.

27. Liem GA, Lau WK, Cai EY. Promoting Mastery-Approach Goals to Support the Success of the "Teach Less, Learn More" Educational Initiative. In: Chia LW Keng JW, Ryan RM, ed. Building Autonomous Learners, Singapore. Springer. 2016:277-302

28. Davies MJ Babkes Stellino M Nichols BA Coleman LM Other-Initiated Motivational Climate and Youth Hockey Players' Good and Poor Sport Behaviors. J Appl Sport Psychol. 2016;28(1):78-96.

29. Miyamoto T, Kamada H, Tamaki A, Moritani T. Low-intensity electrical muscle stimulation induces significant increases in muscle strength and cardiorespiratory fitness. Eur J Sport Sci. 2016:1-7.

30. Fenton SA, Duda JL, Barrett T. Inter-participant variability in daily physical activity and sedentary time among male youth sport footballers: independent associations with indicators of adiposity and cardiorespiratory fitness. J Sports Sci. 2016;34(3):239-51

31. Stathokostas L, Vandervoort AA. The Flexibility Debate: Implications for Health and Function as We Age. Annual Rev Gerontology Geriatrics. 2016;36(1):169-92.

32. Van der Horst N, Van de Hoef S, Reurink G, Huisstede B, Backx F. Return to Play After Hamstring Injuries: A Qualitative Systematic Review of Definitions and Criteria. Sports Med. 2016:1-14.

33. Gaigole R, Patil S. Plyometric training effect on flexibility in female pubertal gymnasts. International Journal of Therapies and Rehabilitation Research 2016;5(1):37-45

34. Suchomel TJ, Nimphius S, Stone MH. The Importance of Muscular Strength in Athletic Performance. Sports Med. 2016 Feb 2. [Epub. ahead of print]:1-31.

35. Stangier C, AbelT, Mierau J, Hollmann W, Strüder HK. Effects of Cycling Versus Running Training on Sprint and Endurance Capacity in Inline Speed Skating. Sports Sci Med. 2016;15(1):41-9.

36. Prieske O, Muehlbauer T, Borde R, Gube M, Bruhn S, Behm DG, et al. Neuromuscular and athletic performance following core strength training in elite youth soccer: Role of instability. Scand J Med Sci Sports. 2016;26(1):48-56.

37. Fowler NE, ReillyT. Assessment of muscle strength asymmetry in soccer players. Contemporary ergonomics. In: Lovesey EJ, ed. Proceedings of the Ergonomics Society's 1993 Annual Conference, Edinburgh, Scotland. London, UK. Taylor \& Francis. 1993;327-32. 